\title{
Parametric study of glycerol and contaminants removal from biodiesel through solvent-aided crystallization
}

\author{
Mohd. Afnan Ahmad ${ }^{1,2}$, Arun Letchumanan', Shafirah Samsuri ${ }^{1,2^{*}} \mathbb{0}$, Wan Nur Athirah Mazli ${ }^{1,2}$ and \\ Juniza Md Saad ${ }^{3}$
}

\begin{abstract}
At present, biodiesel is known as an alternative fuel globally. It is also known that the purification of biodiesel before consumption is mandatory to comply with international standards. Commonly, purification using water washing generates a massive amount of wastewater with a high content of organic compounds that can harm the environment. Therefore, this study applied and tested a waterless method, i.e., the solvent-aided crystallization (SAC), to remove glycerol and other traces of impurities in the crude biodiesel. The parameters of coolant temperature, crystallization time, and stirring rate on the SAC system were investigated. It was discovered that with $14^{\circ} \mathrm{C}$ coolant temperature, 300 RPM and higher cooling time result in the highest percentage of FAME up to 99.54\%, which indicates that contaminants' presence is limited in the purified biodiesel. The use of 1-butanol as the solvent for crystallization process remarkably enhanced the separation and improved the higher biodiesel quality.
\end{abstract}

Keywords: Biodiesel purification, Solvent-aided crystallization, Glycerol, Fatty acid methyl esters

\section{Introduction}

The rise in the economy concerning transportation as well as environmental awareness leads to the use of petroleum-derived fossil fuels. The term biodiesel is referred to as renewable and biodegradable fuel that functions as an alternative in traditional engines (Tyson and McCormick 2006). Vegetable oil, animal fats, and waste cooking oil can be used as feedstock in producing biodiesel such as soybean oil (55\%), canola oil (10\%), corn oil (12\%), recycled used cooking oils, and yellow greases (13\%) in the United States in 2016 (Ambat et al. 2018). Oils from rapeseed, sunflower, palm kernel, and animal fats such as beef tallow and pork lard are also considered significant sources to produce biodiesel. To reserve the decreasing of traditional world fuel and promote

\footnotetext{
*Correspondence: shafirah.samsuri@utp.edu.my

${ }^{1}$ Chemical Engineering Department, Universiti Teknologi PETRONAS,

32610 Seri Iskandar, Perak, Malaysia

Full list of author information is available at the end of the article
}

sustainability to avoid environmental effects, biodiesel is preferred, and it has served as a prominent alternative source of fuel. Compared to petroleum fuel, the use of biodiesel also reduces the greenhouse effects, which can minimize the threat of global warming. Other than that, gasses emitted from biodiesel's combustion have low carbon monoxide content, contributing to the controlled carbon dioxide emissions and air pollution (Mohammed and Bandari 2017).

The process of transesterification is one of the simplest and quickest ways of producing biodiesel. The procedure still induces glycerol as a by-product. Unreacted methanol, residual catalyst, soap, and water are also present in production. After the reaction, glycerol and other by-products are removed from the reaction mixture by a simple gravitational settling process, and the FAME phase washed to remove impurities. However, biodiesel cannot be used directly without purification, which can cause engine knocking or choking on the injector. In addition, the glycerol may accumulate around the 
injector valve heads and affect engine performance (Saleh et al. 2010; Atadashi et al. 2011). In the American Society for Testing and Materials (ASTM D6751), the removal of glycerol and other by-products from the fatty acid methyl ester (FAME) process is mandatory because the purity of the final FAME product is highly stressed. Despite the fact that biodiesel is the only substitute form of fuel that has been recognized in the testing requirements of the 1990 Clean Air Act Amendment and legally registered as a legal motor fuel with the Environmental Protection Agency, ASTM D6751, and EN 14,214 standards ensure the presence of impurities is limited in the FAME layer of biodiesel (Shah and Porter 2014).

Conventionally, biodiesel is purified using water washing, acid washing, and washing with ether and absorbents (Bateni et al. 2017; Berrios and Skelton 2008). Until recently, water washing is the common method for biodiesel purification, but the method uses large quantities of water. Significantly, water use produces a massive amount of polluted effluent. The contaminated wastewater needs to be treated before it is released to the environment due to high $\mathrm{pH}$ values, high biological oxygen demand (BOD), and chemical oxygen demand (COD) contents (Wall et al. 2011; Atadashi 2015). Consequently, a large amount of water consumption is not feasible in treating the produced wastewater (Samsuri et al. 2017).

One of the alternatives to replace the water washing process is by using the dry washing method. This method uses solid adsorbents or ion exchange resins to purify biodiesel. Although it can replace the water washing process, the knowledge of its chemistry and the regeneration of spent adsorbent is still lacking (Atadashi 2015). Besides, a filter is needed to increase the effectiveness of this method in purifying biodiesel. Some researchers have been developing a membrane technology system to purify biodiesel (Torres et al. 2017; Kusworo et al. 2020). Many efforts have been made in controlling membrane fouling. However, the membrane fouling process causes the membrane to have low membrane flux and permeability, which increases the cleaning chemical costs, energy demand, and operating cost of the membrane system and shortens the lifetime of the membrane. Therefore, solvent-aided crystallization (SAC) is introduced to replace the water washing to minimize the difficulties encountered in biodiesel purification.

In this study, SAC was used to purify the biodiesel. SAC is a crystallization method that uses additional assisting agents (e.g. solvents). The use of assisting agent assists and affects the crystallization kinetics favorably. Although this type of crystallization can produce high-purity products, the viscosity of the melt has a negative effect on separation efficiency and the growth rates of the crystal (Eisenbart et al. 2017). The viscous product has difficulty with the nucleation process, growth, and post-treatment process. It will slow the diffusion rate and natural convection and subsequently develop the impure melt layer. Besides, the conventional melt layer crystallization is only suitable for a sample with lower viscosity. The sample used in this study is high in viscosity (i.e. biodiesel and glycerol) (Binhayeeding et al. 2017). In addition, researchers used liquid ammonia and 1-butanol as the additional assisting agents to purify glycerol via crystallization. As a result, both solvents can enhance crystal formation in suspension crystallization, but a 1-butanol solution can decrease the viscosity without affecting the vapor pressure of crystallization substances (Hass and Patterson 1941).

Recent studies have reported that the addition of 1-butanol has altered the kinetics of crystallization by lowering glycerol viscosity, improving melt agitation while stirring and enhancing purification with a high crystal growth rate (Thongboonkerd et al. 2006; Eisenbart and Ulrich 2015). The studies also proved that 1-butanol is the most suitable solvent, which significantly impacts the separation of glycerol and water; therefore, $\mathrm{SAC}$ is seen as a feasible glycerol method purification. On top of that, the traces of 1-butanol can be easily removed completely via evaporation from the mixtures because 1-butanol is discovered to remain largely in the liquid phase (Eisenbart and Ulrich 2016). The purification method via SAC was conducted right after the transesterification process in previous literature, which replaced gravitational settling and water washing (Singh 2011). As a result, high purity of biodiesel (\% FAME purity) was obtained, which confirmed the capability of SAC in removing the contaminants that exist in the biodiesel. Nevertheless, the information of free glycerol content in purified biodiesel is not mentioned, but the higher the FAME purity percentage means, the lesser the contaminants present in the biodiesel and the limitation of the glycerol content (Singh 2011).

Therefore, this study attempts to remove free glycerol from FAME using the SAC method. The SAC method was done right after removing glycerol and contaminants by gravitational settling. The remaining free glycerol and other impurities left in the biodiesel were then removed using this SAC method. The composition of FAME in biodiesel and the total content of free glycerol were determined by using gas chromatography-mass spectrometry (GC-MS). Consequently, by measuring the purity of FAME, the percentage of glycerol and another contaminant such as $\mathrm{K}$ or $\mathrm{Na}$ also can be known. In addition, thermal analysis using differential scanning calorimetry (DSC) and rheometer was also used to analyze biodiesel and glycerol characteristics. 


\section{Materials and methods Materials}

Cooking oil from Buruh brand was purchased from a local market. Methanol (99.97\% purity) and potassium hydroxide $(\mathrm{KOH})$ pellets were supplied by Avantis Laboratory Supply. Meanwhile, ethylene glycol and 1-butanol were provided by Benua Sains Sdn. Bhd. Ethylene glycol solution of $50 \%(\mathrm{v} / \mathrm{v})$ with water was used as the coolant inside the refrigerated bath.

\section{Synthesis of biodiesel via transesterification method}

Figure 1 shows the experimental setup of the transesterification method. About $460 \mathrm{~g}$ of palm oil from Buruh brand was heated in the three-necked flask up to $60{ }^{\circ} \mathrm{C}$. The temperature of palm oil was maintained between 55 and $60{ }^{\circ} \mathrm{C}$ using a recirculating water bath facility. The stirring speed and temperature were controlled by heating and stirring the mantle. About $3.5 \mathrm{~g}$ of $\mathrm{KOH}$ was measured using an enclosed electronic measuring cylinder and dissolved in $79.2 \mathrm{~g}$ of methanol. Then, the methoxide solution was added to the heated palm oil, and the reaction mixture was stirred rapidly for $20 \mathrm{~min}$ at $500 \mathrm{rpm}$ using a magnetic stirrer. Then, the crude biodiesel was transferred into a separatory funnel and left for one day. After the gravitational settling process, the bottom glycerol layer was drained using a stop cock, and the volume of glycerol was recorded. The same step was repeated by draining the remaining biodiesel layer, and the volume was recorded.

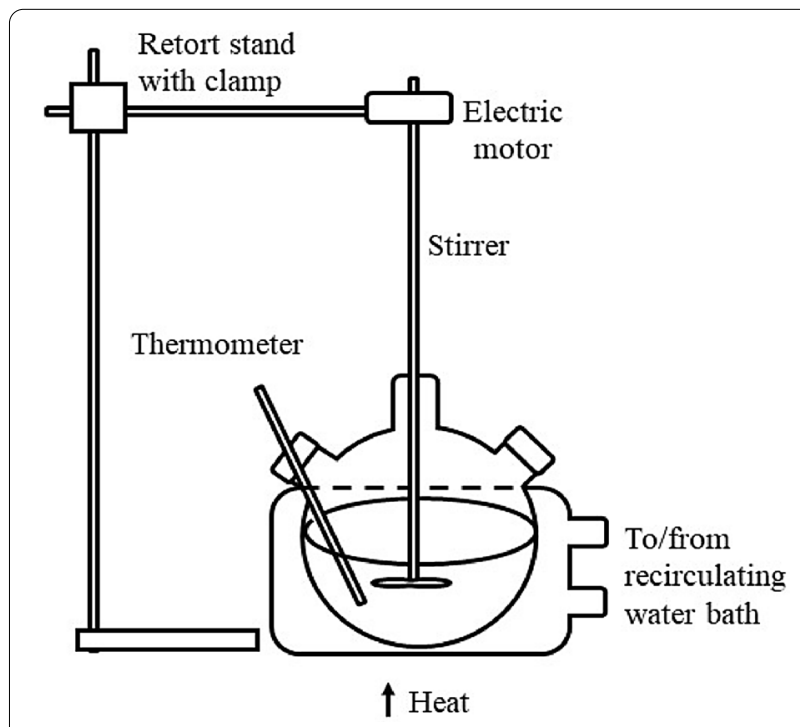

Fig. 1 Transesterification reactor setup for biodiesel production

\section{Glycerol removal via solvent-aided crystallization}

Figure 2 shows the experimental apparatus setup for the SAC system using a cylindrical vessel $(13.5 \times 17 \mathrm{~cm})$. A stainless-steel cylindrical vessel was used for solvent added with crystallizer to avoid the vessel from corroding and minimize the presence of foreign compounds in the solution (Samsuri et al. 2014). The vessel was equipped with a stirrer (EURO-ST 40 D S002, IKA, Malaysia) to stir the crude biodiesel at the solid-liquid interface. This is to allow the user to set the torque and speed for consistent mixing of the solution. Besides, it is to enhance the separation of glycerol as the FAME movement at solid-liquid was well promoted. A refrigerated bath (EYELA Cool ACE CA-1111, TOKYO RIKAKIKAI CO., LTD) was used to maintain the desired temperature sample. Then, the refrigerated bath was turned on, and the temperature was set at $8{ }^{\circ} \mathrm{C}$.

A $500 \mathrm{ml}$ volume of crude biodiesel and 1-butanol solvent with $1 \mathrm{wt}$. \% of concentration was poured into the attached cylindrical vessel inside the refrigerated bath. Then, the stirrer was turned on, and the crystallization time was set for $35 \mathrm{~min}$. Afterwards, stirring was stopped at the designated time, and the vessel was taken out from the refrigerated bath. Two phases of the sample were observed: the solid phase (the glycerol and other impurities) and the liquid phase (the pure biodiesel). The purified biodiesel was collected for further analysis using GC-MS. The experiment was repeated using different operating conditions such as different coolant temperatures $\left(10,12,14\right.$, and $\left.16{ }^{\circ} \mathrm{C}\right)$, stirring speed (100, 200, 400, and $500 \mathrm{rpm})$, and cooling time $(20,25,30$, and $40 \mathrm{~min})$. All the biodiesel samples were evaluated using GC-MS to determine the FAME content as the purity of biodiesel. As shown in Fig. 3a before the purification via the SAC method and Fig. $3 \mathrm{~b}$ the pure biodiesel remained in the liquid phase, and the

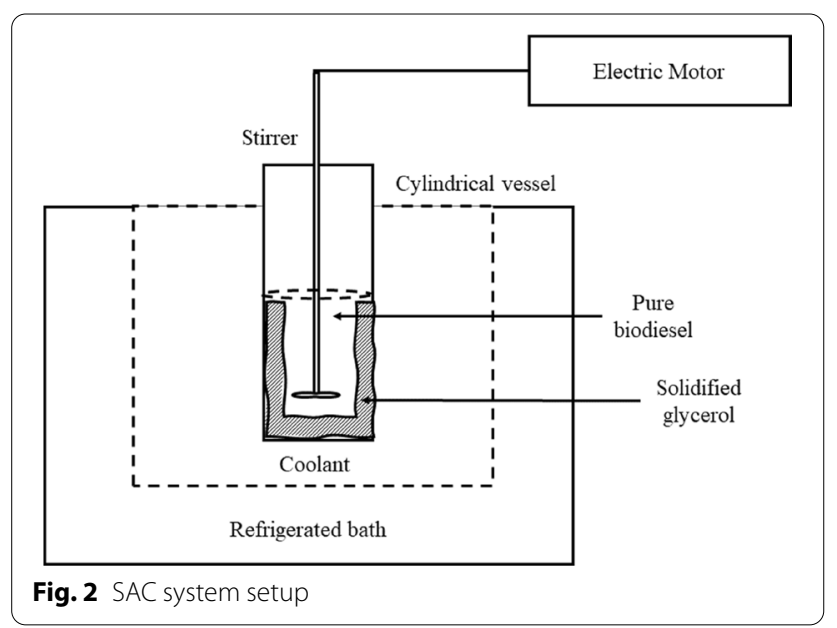



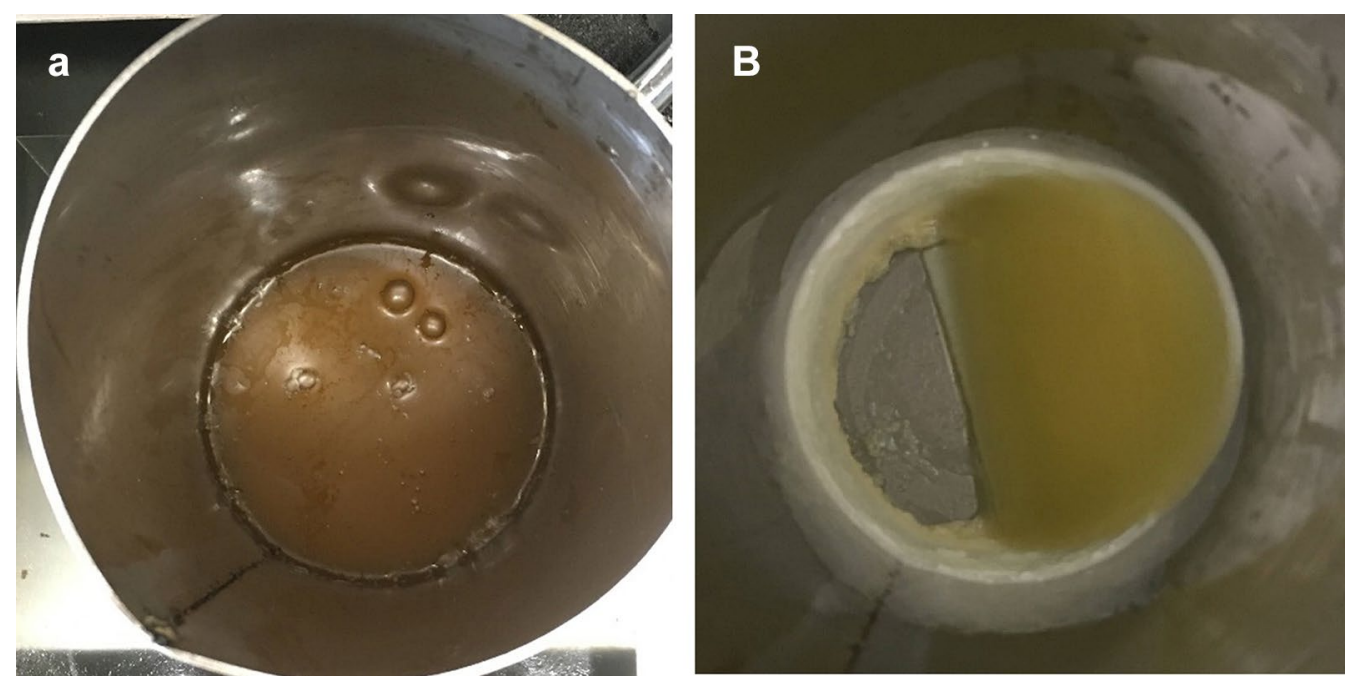

Fig. 3 a Sample solution before SAC method and $\mathbf{b}$ solidified free glycerol attached on vessel surface, and pure biodiesel remained in liquid phase after SAC

solidified free glycerol and other contaminant attached to the vessel surface after SAC.

\section{GC-MS analysis}

The GC-MS Shimadzu (GC-MS QP 2020, Shimadzu, Kyoto, Japan) was used to determine the total FAME content in the biodiesel. A column with an internal diameter of $30 \mathrm{~mm}$ and a film thickness of $0.25 \mu \mathrm{m}$ from SGE and BP-20 (WAX)-polyethylene glycol was used. The chromatogram peaks were generated using the GC-MS solution equipped with $250{ }^{\circ} \mathrm{C}$ of injector temperature, $23^{\circ} \mathrm{C} / \mathrm{min}$ of oven temperature, and increase to $250{ }^{\circ} \mathrm{C}$ and $200{ }^{\circ} \mathrm{C}$ of ion source temperature. Helium gas was also used as the carrier gas, while $n$-heptane was used as the diluent. The purity of each process of purification was calculated using Eq. (1):

$$
\begin{aligned}
& \text { \% Composition of FAME } \\
& =\frac{\text { Peak are of individual component }}{\text { Sum of correction area }} \times 100 \%
\end{aligned}
$$

\section{DSC analysis}

To determine crystallization temperature, both biodiesel and glycerol samples were analyzed using DSC Q2000 (TA Instrument-Waters, LLC, USA). The thermograms for both samples' heat flow were generated using the $\mathrm{Q}$ series (Q2000-2580-DSCQ2000) software. Biodiesel was calibrated to $30^{\circ} \mathrm{C}$ and cooled to $-15{ }^{\circ} \mathrm{C}$ at a rate of $5{ }^{\circ} \mathrm{C} /$ min. Meanwhile, the temperature range for the glycerol sample was 0 to $30{ }^{\circ} \mathrm{C}$ at the same heating rate of $5{ }^{\circ} \mathrm{C} /$ min. DSC analysis is essential to determine biodiesel and glycerol's crystallization temperatures so that the suitable cooling temperature range can be used during purification via SAC.

\section{Rheometer analysis}

Discovery Hybrid Rheometer, DHR-1 (TA Instrument, Elstree, UK)) rotational rheometer with a single wall rotor and the concentric cylinder was used to determine the rheological properties such as viscosity, shear stress, and a shear rate of biodiesel and glycerol. Besides, TA Instrument Trios version 4 software with a flow temperature ramping method. The purpose of this analysis was to justify that the viscosities of biodiesel and glycerol are higher than $0.1 \mathrm{~Pa} \cdot \mathrm{s}$. Therefore, this purification method via SAC can be used or suitable for highly viscous liquids sample (Eisenbart and Ulrich 2016).

\section{Statistical analysis}

The analysis of variance (ANOVA) was utilized to find the significant difference error in this research by using STATISTICA software Version 8.0 Inc., USA. The experiment was conducted with a stirring speed of $100-500$ RPM, a coolant temperature of $8-16^{\circ} \mathrm{C}$, and a crystallization period of 20-40 min. The experiment was repeated three times, with the average values determined. The correlation coefficient $\left(R^{2}\right)$ was used to assess the accuracy of the curves, and a value 0.05 of $\mathrm{p}$-value was considered significant. 


\section{Energy analysis}

An amount of sample (biodiesel) was employed in this labsized experiment as the energy consumption of the biodiesel is determined by SAC method. The SAC's energy consumption is concentrated on the cooling energy (refrigerated bath) and the stirring energy (propeller). As the system carries out the operation, both types of equipment employ the same equation for specific energy consumption $\left(\mathrm{kWh} / \mathrm{m}^{3}\right)$. The specific energy consumption was calculated using Eq. (2), and (3) was used to compute the digital stirrer's power (Power-Torque. 2002; Samsuri et al. 2020):

$$
\begin{aligned}
& \mathrm{SEC}_{\text {equipment }}=\frac{P_{\text {equipment }} \times \eta_{\text {equipment }}}{V_{\text {sample }}} \\
& P_{\text {propeller }}=\frac{T \times N_{\text {rpm }}}{9548.8} .
\end{aligned}
$$

The power of equipment $(\mathrm{kW})$ indicates as $\mathrm{P}$, followed by $\eta$ is the efficiency of the equipment, which has been set at the minimal point $(80 \%)$ for both equipment. $\mathrm{V}$ is the volumetric flowrate $\left(\mathrm{m}^{3} / \mathrm{h}\right)$ in Eq. (2). Next, in Eq. (3) T indicates the torque of the propeller $(0.4 \mathrm{Nm})$, and $N_{\text {rpm }}$ referred the speed of the propeller for each run of experiment. The overall specific energy consumption is shown in Eq. (4), which is the sum of the refrigerated bath and propeller's specific energy consumption:

$$
\mathrm{SEC}_{\text {Total }}=\mathrm{SEC}_{\text {refrigerated bath }}+\mathrm{SEC}_{\text {propeller }}
$$

\section{Results and discussion} Biodiesel analysis by GC-MS

The purity of FAME content after the gravitational settling process was identified using the GC-MS. The chromatogram of crude biodiesel with a graph of intensity versus retention time is plotted in Fig. 4, followed by the

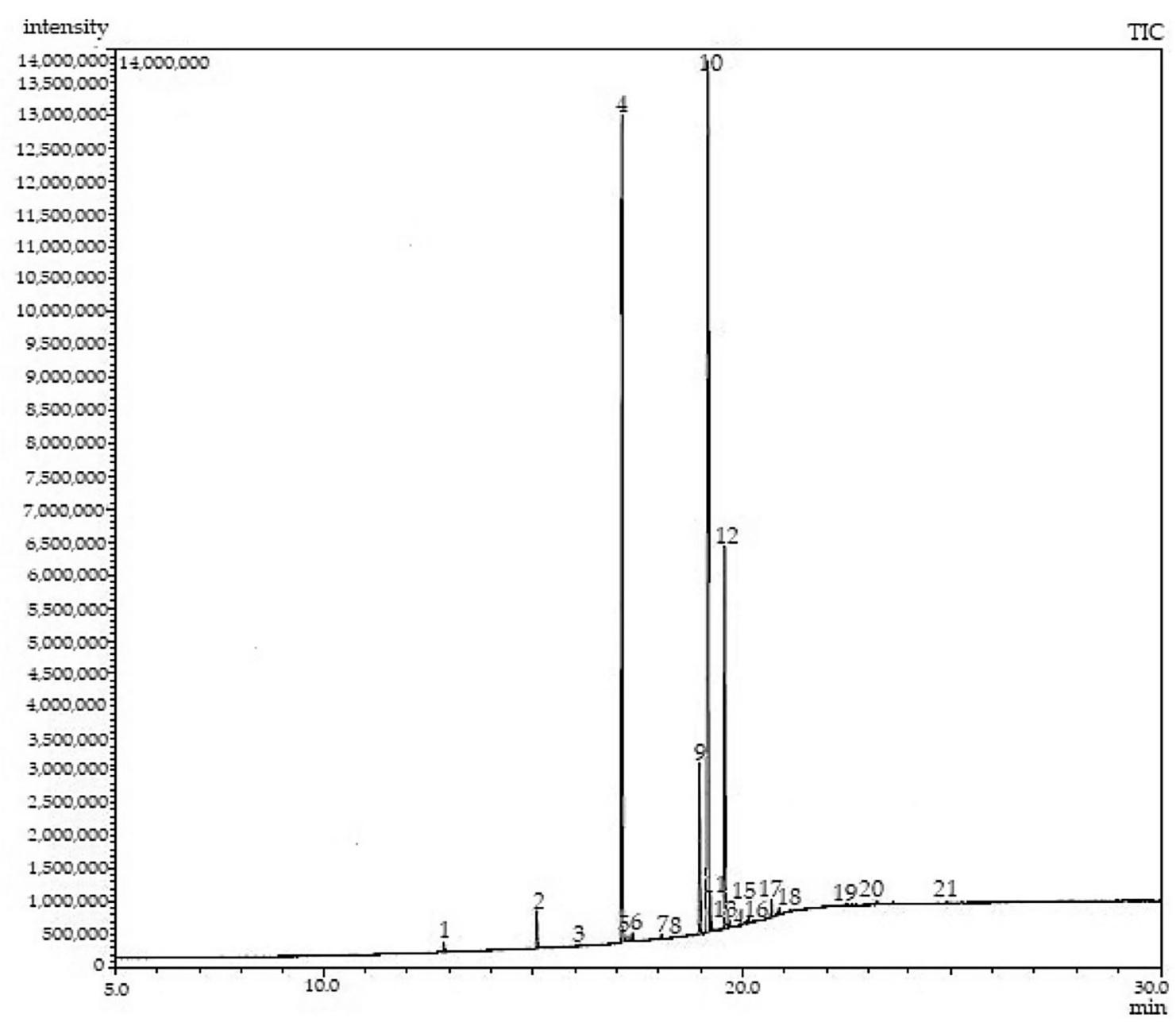

Fig. 4 GC-MS chromatogram of crude biodiesel 
Table 1 GC-MS results for crude biodiesel separated from glycerol after gravitational settling

\begin{tabular}{|c|c|c|c|c|c|}
\hline Peak number & Retention time, $t_{R}$ & Library/ID (systematic name) & Trivial name & Types of fatty acids & $\begin{array}{l}\text { Composition of } \\
\text { FAME\% (purity) }\end{array}$ \\
\hline 1 & 12.870 & Dodecanoic acid & Lauric & Saturated & 0.31 \\
\hline 2 & 15.092 & Tetradecanoic acid & Myristic & Saturated & 1.22 \\
\hline 4 & 17.128 & Hexadecanoic acid & Palmitic & Saturated & 35.08 \\
\hline 6 & 17.375 & 9-Hexadecenoic acid & Palmitoleic & Unsaturated & 0.25 \\
\hline 9 & 18.973 & Octadecanoic acid & Stearic & Saturated & 6.03 \\
\hline 10 & 19.173 & 9-Octadecenoic acid & Oleic & Unsaturated & 40.54 \\
\hline 12 & 19.572 & 9,12-Octadecadienoic acid & Linoleic & Unsaturated & 14.41 \\
\hline 15 & 20.13 & $9,12,15$-Octadecatrienoic acid & Linolenic & Unsaturated & 0.23 \\
\hline \multirow[t]{2}{*}{17} & 20.684 & Eicosanoic acid & Arachidic & Saturated & 0.61 \\
\hline & Total & & & & $98.96 \%$ \\
\hline
\end{tabular}

Table 2 PORIM specification of biodiesel composition (Crabbe et al. 2001)

\begin{tabular}{ll}
\hline Parameters & $\begin{array}{l}\text { PORIM } \\
\text { specification } \\
\text { (\%) }\end{array}$ \\
\hline Lauric & $0.0-0.4$ \\
Myristic & $0.6-1.6$ \\
Palmitic & $41-47$ \\
Palmitoleic & $0-0.6$ \\
Stearic & $3.7-5.6$ \\
Oleic & $38.2-43.5$ \\
Linoleic & $6.6-11.9$ \\
Linolenic & $0.0-0.5$ \\
Arachidic & $0.0-0.8$ \\
Unsaturated fatty acid & $44.8-57.3$ \\
Saturated fatty acid & $45.3-44.5$ \\
\hline
\end{tabular}

peak data in Table 1 to determine the systematic names of fatty acids found in the palm oil-based crude biodiesel.

Table 1 shows the peak number, systematic name (Library/ID), trivial name, and the percentage of FAME composition in palm oil-based biodiesel. According to the Palm Oil Research Institute of Malaysia (PORIM), the type of fatty acids present in palm oil are lauric, myristic, palmitic, palmitoleic, stearic, oleic, linoleic, linolenic, and arachidic. Based on Table 1, the total percentage composition of FAME or biodiesel produced from the gravitational settling method was $98.96 \%$.

In Table 1, the total amount of saturated fatty acid and unsaturated fatty acid was $43.25 \%$ and $55.71 \%$, respectively. The percentage values mostly are between the range specification of biodiesel by PORIM as in Table 2 (Crabbe et al. 2001).

The info such as correction area of individual component and sum of correction area is provided from the table. Thus, the percentage composition of individual
Table 3 GC-MS peak data

\begin{tabular}{lll}
\hline Peak & Retention time & Area \\
\hline 1 & 12.870 & 240,375 \\
2 & 15.092 & 945,990 \\
3 & 16.125 & 38,770 \\
4 & 17.128 & $27,201,103$ \\
5 & 17.311 & 23,262 \\
6 & 17.375 & 193,851 \\
7 & 18.06 & 46,524 \\
8 & 18.279 & 23,262 \\
9 & 18.973 & $4,675,674$ \\
10 & 19.173 & $31,434,798$ \\
11 & 19.224 & 550,535 \\
12 & 19.572 & $11,173,543$ \\
13 & 19.675 & 116,310 \\
14 & 20.072 & 23,262 \\
15 & 20.13 & 178,342 \\
16 & 20.242 & 23,262 \\
17 & 20.684 & 472,995 \\
18 & 20.866 & 62,032 \\
19 & 22.466 & 31,016 \\
20 & 23.192 & 46,524 \\
21 & 24.916 & 38,770 \\
& Total & $77,540,202$ \\
\hline & &
\end{tabular}

FAME can be calculated using Eq. (1). Both data can be obtained from Table 3.

For Peak 3, lauric:

$$
\% \text { Composition of FAME }=\frac{240375}{77540202} \times 100 \%=0.31 \%
$$

\section{DSC analysis}

Figures 5 and 6 show the thermogram of biodiesel and glycerol. The green line indicated heat flow, and 


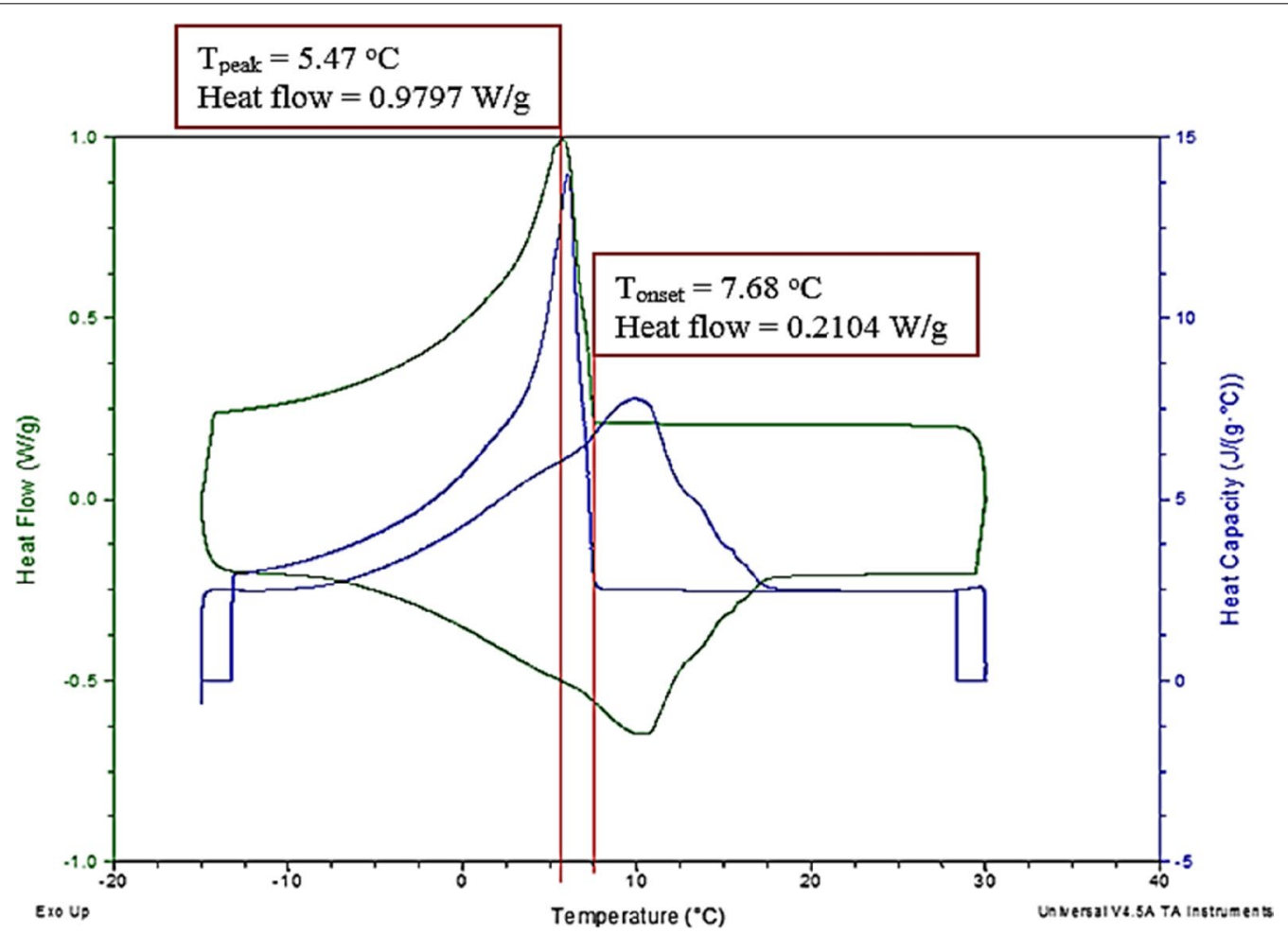

Fig. 5 DSC thermogram for crude biodiesel

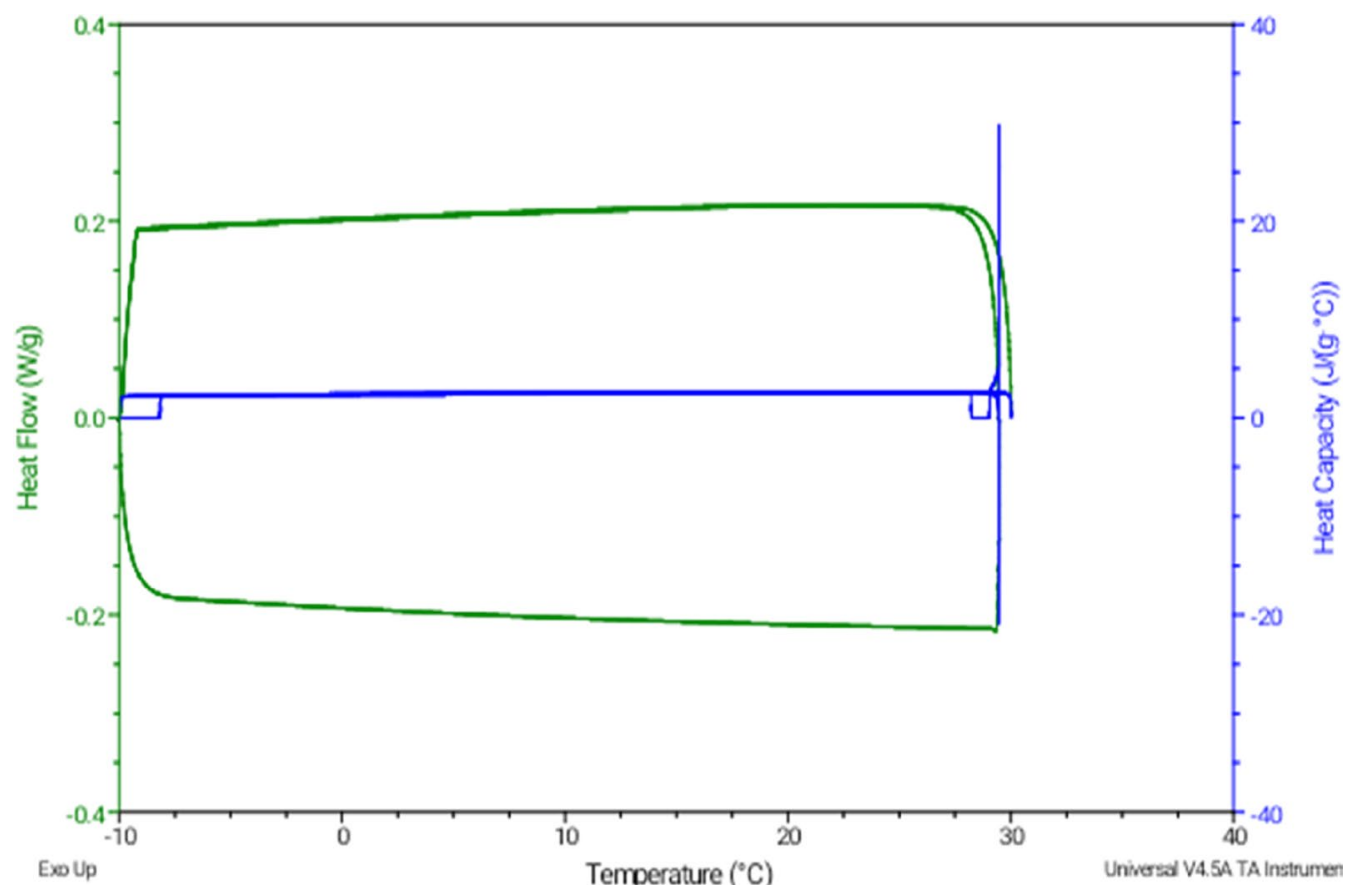

Fig. 6 DSC thermogram for crude glycerol 
the blue line indicated heat capacity, respectively. The analysis was done for the biodiesel sample which was cooled from 30 to $-15{ }^{\circ} \mathrm{C}$ at a constant rate of $5{ }^{\circ} \mathrm{C} / \mathrm{min}$ (green line) in Fig. 5. The appearance of the exothermic peak was due to the heat flow out of the sample because the sample is cooling specifically during crystallization. Crystallization consists of a two-step process, which is nucleation and solid growth (Çaylı and Küsefoğlu 2008). The graph shows that the onset temperature was $7.68{ }^{\circ} \mathrm{C}$, indicating that the crystallization of the biodiesel started to occur. Then, it reached $5.47{ }^{\circ} \mathrm{C}$ show the maximum or peaks as the maximum crystallization temperature of biodiesel.

On the contrary, no visible peaks were observed in the thermogram for the glycerol sample in Fig. 6. The cooling rate for biodiesel was also used on glycerol with a different temperature range $\left(30\right.$ to $\left.-20^{\circ} \mathrm{C}\right)$ and fixed heat flow. The result is also supported by a recent study on the cold properties of fuel mixture and crude glycerol using the DSC analysis, which reported that glycerol has a melting point of $17.8{ }^{\circ} \mathrm{C}$, and no peak was observed during the DSC analysis due to the occurrence of supercooling (Gao et al. 2017).

\section{Rheological properties}

Figure 7 shows that the viscosity of biodiesel at $8.92{ }^{\circ} \mathrm{C}$ was $20.1 \mathrm{~Pa} \cdot \mathrm{s}$. The biodiesel was cooled to $-10{ }^{\circ} \mathrm{C}$ and heated up to $35^{\circ} \mathrm{C}$.

Meanwhile, Fig. 8 shows that the viscosity of glycerol at $12.6{ }^{\circ} \mathrm{C}$ was $0.189 \mathrm{~Pa} \cdot \mathrm{s}$, which was heated from 10 to $20^{\circ} \mathrm{C}$. Biodiesel and glycerol viscosity decreased as temperature increased (Björn et al. 2018; Silva et al. 2015). This is because as temperature rises, fluid flow in a system is increased. Thus, it is proven that the SAC process can be used for highly viscous liquid irrespective of the impact of temperature on viscosity as the viscosity of biodiesel and glycerol was higher than 0.1 Pa.s (Eisenbart and Ulrich 2016).

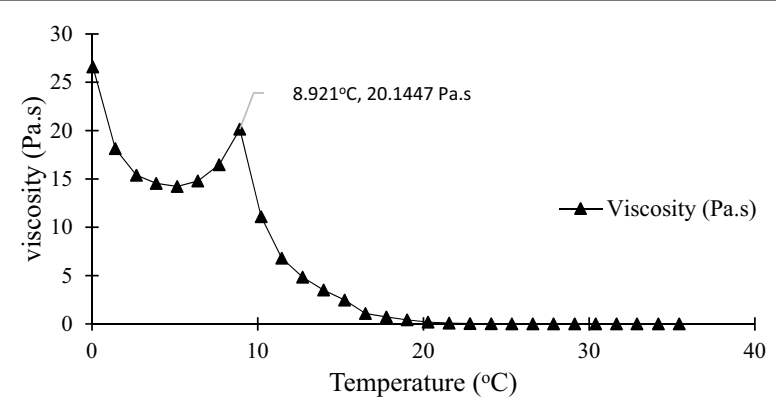

Fig. 7 Viscosity curve of biodiesel

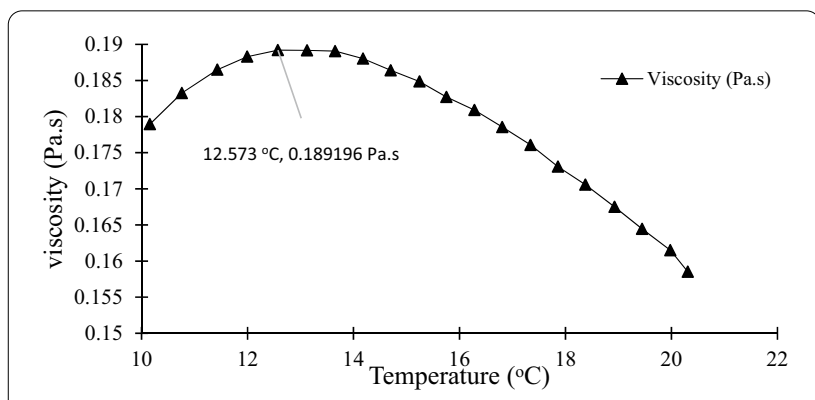

Fig. 8 Viscosity curve of glycerol

\section{Effect of coolant temperature on SAC}

Figure 9 shows that the FAME purity increased when the temperature increased from 8 to $14{ }^{\circ} \mathrm{C}$, and this increase is statistically significant $(p<0.05)$ and show an $R^{2}$ value of 0.89 . The lowest percentage of $99.17 \%$ at $8{ }^{\circ} \mathrm{C}$ was due to the coolant temperature, which is very close to the crystallization temperature of biodiesel as mentioned in Fig. 5. As a result, the lowest FAME purity was obtained by solidifying certain fatty acids due to the slight differences range of temperature between coolant and crystallization temperature of biodiesel.

In addition, the rate of ice crystals or solid growth is controlled by coolant temperature (Amran and Jusoh 2016; Jusoh et al. 2014a). When the temperature is close to the crystallization point, the likelihood of FAME being trapped is higher within the solid layer formed by glycerol and other impurities. Under lower coolant temperature, solid growth rate tends to be greater, which induced a higher methyl ester incorporation into contaminants solid (Samsuri et al. 2017). In addition, the thickness of the solid formed increases as the temperature of the coolant reduces. Nevertheless, the formation of a thicker solid led to high product purity (Mohamad et al. 2017). Hence, the coolant temperature influences the purity of FAME produced.

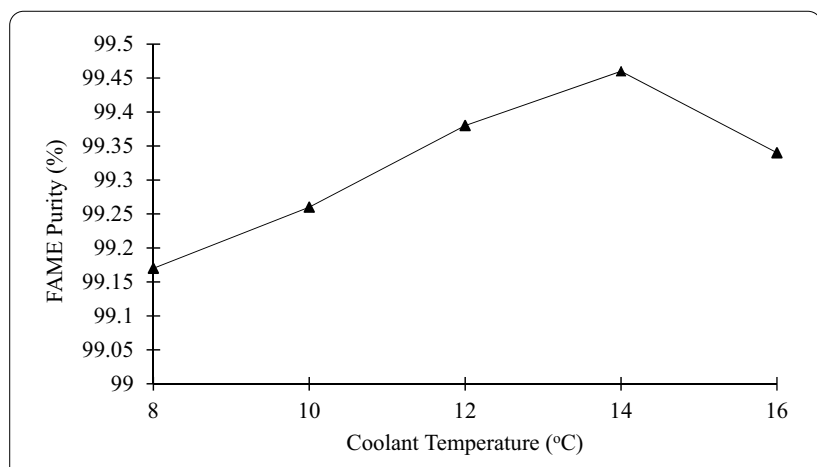

Fig. 9 Graph of FAME Purity against coolant temperature 
In contrast, the highest purity of FAME was achieved at $99.46 \%$ at $14{ }^{\circ} \mathrm{C}$, because this temperature is considered as the favorable coolant temperature. In this state, the FAME did not form in the solid phase and stayed in the liquid phase, while other impurities, including glycerol, were attached to the wall. As observed, solid growth was in an ordered pattern as temperature rises (Romli et al. 2009). In fact, at a higher coolant temperature, the solid can grow in the ordered pattern that enables the pure FAME to free from contaminants and accumulate in the solution and elevates the purity of FAME (Samsuri et al. 2017). However, too high of coolant temperature can affect the solid formation. At higher temperature, the inclusion of solutes can melt and dilute into the solution (Bagdasarov 1988). As a result, the percentage of FAME decreased to $99.34 \%$ at $16{ }^{\circ} \mathrm{C}$. Thus, the coolant temperature of $14{ }^{\circ} \mathrm{C}$ is considered the ideal temperature to obtain high-purity FAME (FAME yield $=99.32 \pm 0.11 \%$ ).

\section{Effect of stirring rate on SAC}

Solution movement assistance is crucial in enhancing the solid to be formed. A propeller was used to perform this SAC system. Besides, a gentle motion is required to maintain the uniform distribution of temperature and the flow of the system (Mohamad et al. 2017). In Fig. 10, an increasing trend observed from (100 to $300 \mathrm{rpm}$ ) and decreases gradually at 400 and $500 \mathrm{rpm}$.

Accordingly, $300 \mathrm{rpm}$ of stirring rate produced a higher percentage of FAME purity (99.54\%) due to the suitable agitation speed to diminish the build-up or accumulation of solute near the liquid-solid interface (Ab. Hamid et al. 2015). Flowrate is closely associated with the circulation of fluid, whereby an increase in flowrate will eventually decrease the advanced rate of the solid front (Miyawaki et al. 2005). As a result, the increase in FAME percentage indicates a better separation efficiency from glycerol and other contaminants. Furthermore, a high circulation flowrate also imposes the development of a high shear force, which can separate the solute from the solution (Jusoh et al. 2014b). High shear force due to high flowrate enables the contaminants solid formed to be carried away easily from the solution, leaving the biodiesel with a higher percentage of FAME. On top of that, the FAME purity was the lowest at $100 \mathrm{rpm}$ (99.40\%). A slower stirring speed induces slower movement of solutions and reduces the efficiency of separation. Thus, it explains that mild agitation is preferred compared to slower stirring speed.

For the stirring rate of 400 and $500 \mathrm{rpm}$, the reduction of FAME purity was $99.49 \%$ and $99.42 \%$, respectively. The FAME yield was significant $(p<0.05)$ with the $R^{2}$ value of 0.96 . This is because the higher stirring speed can erode the solid formed onto the vessel wall (Romli et al. 2009). The turbulence flow was created inside the system when the agitation was more heightened. Thus, the solidified contaminant was mixed with the biodiesel, eventually reducing the FAME purity. Besides, vigorous stirring will promote a slower solidification rate and reduce the liquid phase's final concentration (Mohamad et al. 2017; Ab. Hamid et al. 2015). Consequently, the contaminants crystallization rate is slowed down, limiting the heat transfer, and finally decreases the final concentration of FAME $($ FAME yield $=99.47 \pm 0.06 \%)$.

\section{Effect of crystallization time on SAC}

The plot $(p<0.05)$ in Fig. 11 shows that FAME purity increased when the temperature increased up to $99.46 \%$ $\left(R^{2}=0.93\right)$. This is because longer crystallization time enhances the crystallization process. When a solution is stirred for adequate time, it provides longer residence time to be in the crystallizer and allows thicker solid layer formation (Jusoh et al. 2014b). Thus, more contaminants were trapped within the thick solid layer and left the unfrozen biodiesel with higher FAME purity. At 20 and $25 \mathrm{~min}$, the FAME purity remained unchanged with $99.37 \%$, indicating that the crystallization process just

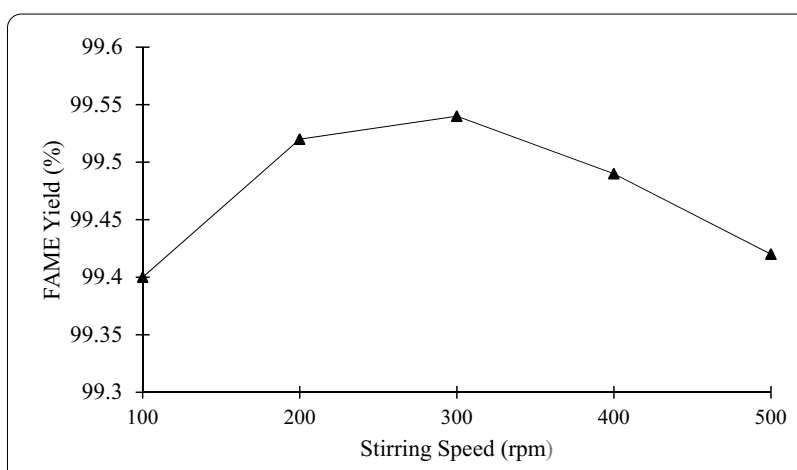

Fig. 10 Graph of FAME purity against stirring speed

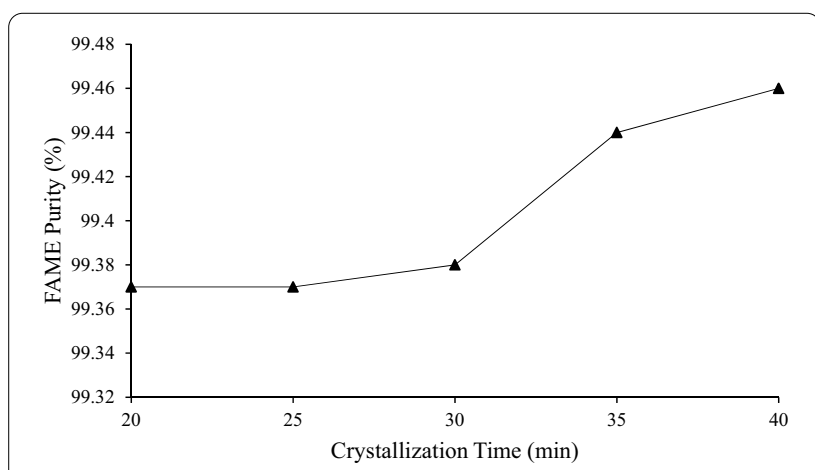

Fig. 11 Graph of FAME purity against crystallization time 
started to occur (FAME yield $=99.40 \pm 0.04 \%$ ). Therefore, sufficient cooling time is needed for better purity of biodiesel. However, a crystallization time longer than $40 \mathrm{~min}$ was not conducted further in this study.

In the F-test, the coefficients are added to the system and being analyzed. The experiment results might lead to improvements in system parameters and make the system better match in the experiment. The calculated F-value was 4.84, as shown in Table 4, which is greater than the tabulated $F$-value of $95 \%$ confidence $\left(F_{0.05}, 3,11\right)$ which is 3.587 thus, that the regression model as a whole is statistically significant.

\section{Energy consumption}

Nowadays, the most challenging part for the industry is reducing energy consumption to reduce operational costs (Innocenzi and Prisciandaro 2021). The energy consumption for SAC method was calculated using the power of equipment measured through the term of the energy used for the contaminant removal. The energy consumption was varied for each run by the formation of the solid.

Table 4 ANOVA result for regression

\begin{tabular}{lllll}
\hline Source & Sum of squares & $\begin{array}{l}\text { Degree of } \\
\text { freedom }\end{array}$ & Mean squares & F-value \\
\hline Regression & 0.074 & 3 & 0.0246 & 4.847 \\
Residual & 0.056 & 11 & 0.0050 & \\
Total & 0.130 & 14 & & \\
$R^{2}$ & 0.569 & & & \\
\hline
\end{tabular}

The highest total energy consumption $323.0072360 \mathrm{kWh} /$ $\mathrm{m}^{3}$ was achieved due to the longer time of the experiment conducted.

The optimum parameter for total energy consumption is the highest number of energies consumed. Thus, based on the analysis of the energy consumption of contaminant removal at the lower crystallization time $161.5036180 \mathrm{kWh} / \mathrm{m}^{3}$ of energy consumption was achieved. This shows that the crystallization time was the crucial parameter to be considered. To conclude that, to compare both results, the lower energy value should be taken into account as both FAME purity show almost similar numbers (Table 5).

\section{Conclusion}

The SAC system has proven to remove contaminants from crude biodiesel, which is applicable as a waterless method for biodiesel purification. This study aims to determine the effectiveness of free glycerol from FAME using the SAC method. The highest FAME purity and the lower energy consumption removal of contaminants from biodiesel was $99.37 \%$ and $161.5036180 \mathrm{kWh} / \mathrm{m}^{3}$. Therefore, SAC must be operated at a coolant temperature of $14{ }^{\circ} \mathrm{C}$, stirring rate of $300 \mathrm{rpm}$, and crystallization time of $20 \mathrm{~min}$. It is essential to work with precision to form pure contaminants solid and recover the biodiesel. Thus, the increase of final FAME content in biodiesel indicates the presence of impurities is limited.

Table 5 Calculation of energy consumption

\begin{tabular}{|c|c|c|c|c|c|c|c|c|}
\hline Run & $\begin{array}{l}\text { Stirring } \\
\text { rate (RPM) }\end{array}$ & Time (h) & FAME purity (\%) & $\begin{array}{l}\text { Volume of } \\
\text { sample }\left(\mathrm{m}^{3}\right)\end{array}$ & $\begin{array}{l}\text { Volumetric } \\
\text { flowrate } \\
\left(\mathrm{m}^{3} / \mathrm{h}\right)\end{array}$ & $\begin{array}{l}\text { Energy of } \\
\text { propeller (kWh/ } \\
\mathrm{m}^{3} \text { ) }\end{array}$ & $\begin{array}{l}\text { Energy } \\
\text { refrigerated } \\
\left(\mathrm{kWh} / \mathrm{m}^{3}\right)\end{array}$ & Total energy $\left(\mathrm{kWh} / \mathrm{m}^{3}\right)$ \\
\hline 1 & 300 & 0.583 & 99.17 & 0.0005 & 0.000857 & 2.9311 & 279.82 & 282.7525805 \\
\hline 2 & 300 & 0.583 & 99.26 & 0.0005 & 0.000857 & 2.9311 & 279.82 & 282.7525805 \\
\hline 3 & 300 & 0.583 & 99.38 & 0.0005 & 0.000857 & 2.9311 & 279.82 & 282.7525805 \\
\hline 4 & 300 & 0.583 & 99.46 & 0.0005 & 0.000857 & 2.9311 & 279.82 & 282.7525805 \\
\hline 5 & 300 & 0.583 & 99.34 & 0.0005 & 0.000857 & 2.9311 & 279.82 & 282.7525805 \\
\hline 6 & 100 & 0.583 & 99.40 & 0.0005 & 0.000857 & 0.9768 & 279.82 & 280.7982609 \\
\hline 7 & 200 & 0.583 & 99.52 & 0.0005 & 0.000857 & 1.9536 & 279.82 & 281.7750709 \\
\hline 8 & 300 & 0.583 & 99.54 & 0.0005 & 0.000857 & 2.9311 & 279.82 & 282.7525805 \\
\hline 9 & 400 & 0.583 & 99.49 & 0.0005 & 0.000857 & 3.9058 & 279.82 & 283.7272919 \\
\hline 10 & 500 & 0.583 & 99.42 & 0.0005 & 0.000857 & 4.8828 & 279.82 & 284.7043351 \\
\hline 11 & 300 & 0.333 & 99.37 & 0.0005 & 0.001501 & 1.6742 & 159.82 & 161.5036180 \\
\hline 12 & 300 & 0.416 & 99.37 & 0.0005 & 0.001201 & 2.0915 & 199.66 & 201.7582736 \\
\hline 13 & 300 & 0.500 & 99.38 & 0.0005 & 0.001000 & 2.5138 & 239.98 & 242.4979250 \\
\hline 14 & 300 & 0.583 & 99.44 & 0.0005 & 0.000857 & 2.9311 & 279.82 & 282.7525805 \\
\hline 15 & 300 & 0.666 & 99.46 & 0.0005 & 0.000750 & 3.3484 & 319.65 & 323.0072360 \\
\hline
\end{tabular}




\section{Acknowledgements}

The authors would like to thank Universiti Teknologi PETRONAS for providing financial aid via YUTP-FRG (Cost Centre: 015LC0-079) and facilities support from Centralised Analytical Lab (CAL) services and HICoE Centre for Biofuel and Biochemical Research (CBBR) for facilities support. Support from the Ministry of Education Malaysia through the HICOE award to CBBR is duly acknowledged.

\section{Authors' contributions}

MAA wrote the manuscript, AL performed experiments and analyzed data, SS supervised the works done by MAA and AL. WNAM and JMdS revised the manuscript. All authors read and approved the final manuscript.

\section{Funding}

All sources of funding for the research have been declared in the

"Acknowledgements".

\section{Availability of data and materials}

All data generated or analyzed during this study are included in this published article [and its additional information files].

\section{Declarations}

\section{Ethics approval and consent to participate}

The manuscript does not involve human participants, human data, or human tissue.

\section{Consent for publication}

Not applicable.

\section{Competing interests}

The authors declare that they have no competing interests.

\section{Author details}

${ }^{1}$ Chemical Engineering Department, Universiti Teknologi PETRONAS, 32610 Seri Iskandar, Perak, Malaysia. ${ }^{2} \mathrm{HICoE}$ Centre for Biofuel and Biochemical Research (CBBR), Universiti Teknologi PETRONAS, 32610 Seri Iskandar, Perak, Malaysia. ${ }^{3}$ Department of Science and Technology, Faculty of Humanities, Management and Science, Universiti Putra Malaysia, Nyabau Road, 97008 Bintulu, Sarawak, Malaysia.

Received: 31 March 2021 Accepted: 20 June 2021

Published online: 29 June 2021

\section{References}

Ab Hamid F, Rahim N, Johari A, Ngadi N, Zakaria Z, Jusoh M (2015) Desalination of seawater through progressive freeze concentration using a coil crystallizer. Water Supply 15(3):625-631. https://doi.org/10.2166/ws.2015.019

Ambat I, Srivastava V, Sillanpää M (2018) Recent advancement in biodiesel production methodologies using various feedstock: a review. Renew Sustain Energy Rev 90:356-369. https://doi.org/10.1016/j.rser.2018.03.069

Amran N, Jusoh M (2016) Effect of coolant temperature and circulation flowrate on the performance of a vertical finned crystallizer. Procedia Eng 148:1408-1415. https://doi.org/10.1016/j.proeng.2016.06.576

Atadashi I (2015) Purification of crude biodiesel using dry washing and membrane technologies. Alex Eng J 54(4):1265-1272. https://doi.org/10. 1016/j.aej.2015.08.005

Atadashi I, Aroua M, Aziz A (2011) Biodiesel separation and purification: a review. Renew Energy 36(2):437-443. https://doi.org/10.1016/j.renene. 2010.07.019

Bagdasarov K (1988) The problems of high-temperature crystallization. Progr Cryst Growth Charact 16:59-80. https://doi.org/10.1016/0146-3535(88) 90015-9

Bateni H, Saraeian A, Able C (2017) A comprehensive review on biodiesel purification and upgrading. Biofuel Res J 4(3):668-690. https://doi.org/10. 18331/bri2017.4.3.5

Berrios M, Skelton R (2008) Comparison of purification methods for biodiesel. Chem Eng J 144(3):459-465. https://doi.org/10.1016/j.cej.2008.07.019
Binhayeeding N, Klomklao S, Sangkharak K (2017) Utilization of waste glycerol from biodiesel process as a substrate for mono-, di-, and triacylglycerol production. Energy Procedia 138:895-900. https://doi.org/10.1016/j. egypro.2017.10.130

Björn A, Šafarič L, Karlsson A, Danielsson Å, Ejlertsson J, Svensson B, Yekta S (2018) Substrate and operational conditions as regulators of fluid properties in full-scale continuous stirred-tank biogas reactors -implications for rheology-driven power requirements. Water Sci Technol 78(4):814-826. https://doi.org/10.2166/wst.2018.352

Çaylı G, Küsefoğlu S (2008) Increased yields in biodiesel production from used cooking oils by a two-step process: comparison with one step process by using TGA. Fuel Process Technol 89(2):118-122. https://doi.org/10.1016/j. fuproc.2007.06.020

Crabbe E, Nolasco-Hipolito C, Kobayashi G, Sonomoto K, Ishizaki A (2001) Biodiesel production from crude palm oil and evaluation of butanol extraction and fuel properties. Process Biochem 37(1):65-71. https://doi. org/10.1016/s0032-9592(01)00178-9

Eisenbart FJ, Ulrich J (2015) Solvent-aided layer crystallization—case study glycerol-water. Chem Eng Sci 133:24-29

Eisenbart F, Ulrich J (2016) Solvent-aided layer crystallization of glycerol - posttreatment and the influence of agitation. Chem Eng Technol 39(7):12511256. https://doi.org/10.1002/ceat.201600029

Eisenbart F, Angermeier N, Ulrich J (2017) Production of highly dry glycerol by solvent-aided melt layer crystallization. J Cryst Growth 469:191-196. https://doi.org/10.1016/j.jcrysgro.2016.09.001

Gao W, Zhang M, Wu H (2017) Differential scanning calorimetry studies on the cold flow properties of fuel mixtures from bio-oil, crude glycerol, methanol, and/or biochar. Energy Fuels 31(8):8348-8355. https://doi.org/ 10.1021/acs.energyfuels.7b01475

Hass H, Patterson J (1941) Purification of glycerol by crystallization. Ind Eng Chem 33(5):615-616. https://doi.org/10.1021/ie50377a015

Innocenzi V, Prisciandaro M (2021) Technical feasibility of biodiesel production from virgin oil and waste cooking oil: Comparison between traditional and innovative process based on hydrodynamic cavitation. Waste Manage 122:15-25. https://doi.org/10.1016/j.wasman.2020.12.034

Jusoh M, Mohamed-Nor N, Zakaria Z (2014b) Progressive freeze concentration of coconut water. Jurnal Teknologi 67:2. https://doi.org/10.11113/jt.v67. 2734

Jusoh M, Yahya N, Ab. Hamid F, Safiei N (2014a) Effect of coolant temperature on progressive freeze concentration of refined, bleached and deodorised palm oil. Jurnal Teknologi 69:4. https://doi.org/10.11113/jt.v69.3168

Kusworo T, Widayat W, Utomo D, Pratama Y, Arianti R (2020) Performance evaluation of modified nanohybrid membrane polyethersulfone-nano $\mathrm{ZnO}$ (PES-nano $\mathrm{ZnO}$ ) using three combination effect of PVP, irradiation of ultraviolet and thermal for biodiesel purification. Renew Energy 148:935-945. https://doi.org/10.1016/j.renene.2019.10.177

Miyawaki O, Liu L, Shirai Y, Sakashita S, Kagitani K (2005) Tubular ice system for scale-up of progressive freeze-concentration. J Food Eng 69(1):107-113. https://doi.org/10.1016/j.jfoodeng.2004.07.016

Mohamad M, Ngadi N, Wong S, Jusoh M, Yahya N (2017) Prediction of biodiesel yield during transesterification process using response surface methodology. Fuel 190:104-112. https://doi.org/10.1016/j.fuel.2016.10. 123

Mohammed A, Bandari C (2017) Lab-scale catalytic production of biodiesel from waste cooking oil-a review. Biofuels 11(4):409-419. https://doi. org/10.1080/17597269.2017.1370882

Power-Torque (2002) Retrieved from WEN Technology Inc. http://wensensors. com/unipower/calculators/power_torque.asp

Romli A, Abidin M, Md Akil H (2009) Journal search results-Cite This for Me. Sci Res J 6(1):31. https://doi.org/10.24191/srj.v6i1.5623

Saleh J, Tremblay A, Dubé M (2010) Glycerol removal from biodiesel using membrane separation technology. Fuel 89(9):2260-2266. https://doi.org/ 10.1016/j.fuel.2010.04.025

Samsuri S, Aini Amran N, Zheng L, Mohd Bakri M (2017) Effect of coolant temperature and cooling time on fractional crystallization of biodiesel and glycerol. Malays J Fundam Appl Sci 13(4):676-679. https://doi.org/10. 11113/mjfas.v13n4.925

Samsuri S, Jian N, Jusoh F, Hernández Yáñez E, Yahya N (2020) Solvent-aided crystallization for biodiesel purification. Chem Eng Technol 43(3):447-456. https://doi.org/10.1002/ceat.201900433 
Shah R, Porter S (2014) Evolution of biodiesel testing standards and specifications globally. Biofuels 5(1):17-19. https://doi.org/10.4155/bfs.13.70

Silva L, Santos C, Ribeiro J, Souza C, Sant'Ana, A (2015) Rheological analysis of vegetable oils used for biodiesel production in Brazil. Revista De Engenharia Térmica 14(2):31. https://doi.org/10.5380/reterm.v14i2.62129

Singh R (2011) Analysis of energy usage at membrane water treatment plants. Desalin Water Treat 29(1-3):63-72. https://doi.org/10.5004/dwt.2011.2988

Thongboonkerd V, Semangoen T, Chutipongtanate S (2006) Factors determining types and morphologies of calcium oxalate crystals: Molar concentrations, buffering, $\mathrm{pH}$, stirring and temperature. Clin Chim Acta 367(1-2):120-131. https://doi.org/10.1016/j.cca.2005.11.033

Torres J, Rodriguez N, Arana J, Ochoa N, Marchese J, Pagliero C (2017) Ultrafiltration polymeric membranes for the purification of biodiesel from ethanol. J Clean Prod 141:641-647. https://doi.org/10.1016/j.jclepro.2016. 09.130
Tyson K, McCormick R (2006) Biodiesel handling and use guidelines. National Renewable Energy Laboratory.

Wall J, Van Gerpen J, Thompson J (2011) Soap and glycerin removal from biodiesel using waterless processes. Trans ASABE 54(2):535-541. https:// doi.org/10.13031/2013.36456

\section{Publisher's Note}

Springer Nature remains neutral with regard to jurisdictional claims in published maps and institutional affiliations.

\section{Submit your manuscript to a SpringerOpen ${ }^{\odot}$ journal and benefit from:}

- Convenient online submission

- Rigorous peer review

- Open access: articles freely available online

- High visibility within the field

- Retaining the copyright to your article

Submit your next manuscript at $\boldsymbol{\nabla}$ springeropen.com 